\title{
Comportamento do 2,4-D + picloram em Latossolo Vermelho Amarelo
}

\author{
Behavior of 2,4-D + picloram Latosol Red-Yellow \\ Mauricio Franceschi ${ }^{1 *}$, Oscar Mitsuo Yamashita ${ }^{2}$, \\ Sayonara Andrade do Couto Moreno Arantes 3 , Sérgio Plens Andrade ${ }^{4}$
}

Resumo - O 2,4-D e o picloram são moléculas muito utilizadas no controle de plantas daninhas em pastagens. Estudar o destino destas moléculas em solo da Amazônia é de extrema importância para avaliar o potencial de contaminação de águas subterrâneas. O presente trabalho teve como objetivo determinar a lixiviação de doses crescentes de 2,4-D + picloram em Latossolo Vermelho Amarelo Distrófico. Para isso, amostras desse solo foram usadas como substrato para preenchimento de tubos de PVC com $10 \mathrm{~cm}$ de diâmetro e $50 \mathrm{~cm}$ de comprimento. Os tratamentos constituíram da combinação de cinco doses 0,$125 ; 0,25 ; 0,5$ e $1,0 \%$ de um litro do produto comercial Tordon ${ }^{\circledR}$ mais uma testemunha sem aplicação e seis profundidades de amostragem nas colunas $(0 ; 8 ; 16 ; 24$; 32 e $40 \mathrm{~cm}$ ). Utilizou-se o pepino como espécie bioindicadora onde foram analisadas as seguintes variáveis: fitointoxicação, altura de plantas, comprimento radicular e área foliar. Realizou-se o experimento em delineamento inteiramente casualizado, com quatro repetições. Verificou-se que houve lixiviação do herbicida 2,4-D + picloram em Latossolo Vermelho-Amarelo Distrófico e que essa foi mais intensa com o aumento das doses dos herbicidas, chegando a ser lixiviado ao longo de toda a coluna estudada.

Palavras-chave: auxinas, fitointoxicação, lixiviação, pepino, percolação

Abstract - 2,4-D and picloram are molecules much used in the control of weeds in pastures. Study the fate of these molecules in Amazonian soil is of extreme importance in assessing the potential for contamination of groundwater. The objective of the present work was to determine the leaching of increasing doses of 2,4-D + picloram herbicide in Dystrophic Yellow Red Latosol. For this, samples of this soil were used as substrate to fill PVC pipes with $10 \mathrm{~cm}$ in diameter and $50 \mathrm{~cm}$ in length. The treatments consisted of a combination of five doses $0.125 ; 0.25 ; 0.5$ and $1.0 \%$ of one liter of the Tordon ${ }^{\circledR}$ commercial product plus one control without application and six sampling depths in the columns $(0 ; 8 ; 16 ; 24 ; 32$ and $40 \mathrm{~cm})$. The cucumber was used as bioindicator species where the following variables were analyzed: phytotoxification, plant height, root length and leaf area.

Recebido: Janeiro 27, 2017. Aceito: Agosto 30, 2017.

${ }^{1}$ Departamento de Agronomia, Instituto de Ciências Agrárias e Ambientais, Universidade Federal de Mato Grosso - UFMT, Av. Alexandre Ferronato, 1200, Distrito Industrial, CEP 78550-000, Sinop, MT, Brasil.

E-mail: mauriciofranceschi123@hotmail.com

${ }^{2}$ Departamento de Agronomia, Faculdade de Ciências Biológicas e Agrárias, Universidade do Estado de Mato Grosso - UNEMAT, Campus de Alta Floresta, Alta Floresta, MT, Brasil. E-mail: yama@unemat.br

${ }^{3}$ Instituto de Ciências Agrárias e Ambientais, Universidade Federal de Mato Grosso - UNEMAT, Sinop, MT, Brasil. E-mail: sayocm@ufmt.br

${ }^{4}$ Departamento de Agronomia, Instituto de Ciências Agrárias e Ambientais, Universidade Federal de Mato Grosso UFMT, Sinop, MT, Brasil. E-mail: sergioplens@agronomo.eng.br 
The experiment was carried out in a completely randomized design with four replications. It was verified that leaching of the herbicide 2,4-D + picloram in Dystrophic Red-Yellow Latosol and that this one was more intense with the increase of the doses of the herbicides, arriving to be leached throughout the studied column.

Keywords: auxins, phytotoxification, leaching, cucumber, percolation

\section{Introdução}

Com a predominância de pastagens degradadas no Brasil em consequência do manejo inadequado do solo (Dias-Filho, 2014), o controle das plantas daninhas é um dos fatores indispensáveis para melhoria dos índices de produtividade da atividade agropecuária. Devido ao baixo custo e eficácia no controle de plantas indesejáveis, o método químico é o mais utilizado (Pellegrini et al., 2010).

Umas das principais moléculas utilizadas tem sido o 2,4-D e o picloram, que compõem a maioria das formulações comerciais recomendadas para pastagens (Braga et al., 2013), os quais têm contribuído de maneira substancial para a expansão e o desenvolvimento do agronegócio brasileiro. No entanto, o controle químico vem sendo empregado de forma intensa e abusiva, gerando grande preocupação devido aos problemas de contaminação ambiental (Santos et al., 2006).

O picloram, muitas vezes associado ao 2,4-D são usados em aplicações diretas no toco, imediatamente após o corte da planta, para o controle de plantas daninhas de folhas largas de porte arbóreo, arbustivo ou subarbustivo em áreas de pastagens. Sua recomendação varia entre 3 a 4\% (3,0 a 4,0 L do produto em 97,0-96,0 L de água). Como não há uma recomendação da quantidade da mistura à ser aplicada por área do toco, estas aplicações podem concentrar uma quantidade de herbicida maior, quando comparadas a uma aplicação em área total. Sendo assim, há a necessidade de estudar também altas doses dessas moléculas, avaliando seu comportamento no solo e os riscos ao meio ambiente.

O picloram vem sendo utilizado em larga escala pela eficiência na morte de dicotiledôneas de difícil controle que se desenvolvem em áreas de pastagens. Esta molécula, que pertence ao grupo das auxinas sintéticas apresenta como principal problema a possibilidade de contaminação de organismos não alvos, podendo causar intoxicação em espécies dicotiledôneas sensíveis tais como a soja, feijão, algodão dentre outras, quando cultivadas em sucessão (Silva et al., 2007). Além disso, podem causar problemas ambientais pela sua lixiviação para camadas mais profundas no perfil do solo, com alto potencial de contaminação de águas superficiais e subterrâneas (Assis et al., 2011). O transporte de herbicidas no solo representa um dos processos envolvidos na dissipação desses compostos, sendo assim, o conhecimento do processo de lixiviação apresenta aspectos importantes, pois o destino dos herbicidas é essencial para a avaliação do risco de impacto ambiental decorrentes da aplicação (Mancuso et al., 2011; Possamai, 2012). Esse problema se torna ainda mais grave quando se constata que são raros os estudos de comportamento de herbicidas em solos tropicais (D'Antonino et al., 2009).

O objetivo do trabalho foi determinar a lixiviação do herbicida 2,4-D + picloram em Latossolo Vermelho Amarelo Distrófico após chuva simulada de $40 \mathrm{~mm}$ nas dosagens de $0 ; 0,125 ; 0,25 ; 0,5$ e $1 \%$ de um litro do produto comercial Tordon ${ }^{\circledR}$.

\section{Material e métodos}

O solo utilizado foi coletado em área de mata virgem, onde não havia histórico de aplicações de herbicidas (Tabela 1). O solo foi classificado como Latossolo Vermelho Amarelo Distrófico de textura argilosa (EMBRAPA, 2013).

Para a montagem do experimento foram utilizados tubos de PVC de $10 \mathrm{~cm}$ de diâmetro e $50 \mathrm{~cm}$ de comprimento, os quais foram cortados longitudinalmente, parafinados internamente 
Tabela 1. Caracterização física e química do solo utilizado no experimento.

\begin{tabular}{|c|c|c|c|c|c|c|c|c|c|}
\hline \multicolumn{10}{|c|}{$\begin{array}{c}\text { Análise granulométrica (\%) } \\
\text { Textura Argilosa }\end{array}$} \\
\hline & Silte & & \multicolumn{4}{|c|}{ Silte } & \multicolumn{3}{|c|}{ Argila } \\
\hline \multicolumn{3}{|c|}{4,1} & \multicolumn{4}{|c|}{4,1} & \multicolumn{3}{|c|}{53,8} \\
\hline \multicolumn{10}{|c|}{ Análise química } \\
\hline $\mathbf{p H}$ & $\mathbf{P}$ & $\mathbf{K}^{+}$ & $\mathrm{Ca}^{+2}$ & $\mathbf{M g}^{+2}$ & $\mathrm{Al}^{+3}$ & $\mathbf{H}+\mathbf{A l}$ & $\begin{array}{c}\text { CTC } \\
\text { Efetiva }\end{array}$ & $\begin{array}{c}\text { CTC } \\
\text { Potencial }\end{array}$ & $\mathbf{V}$ \\
\hline $\mathrm{H}_{2} \mathrm{O}$ & \multicolumn{2}{|c|}{$\mathrm{mg} \mathrm{dm}^{-3}$} & \multicolumn{6}{|c|}{ 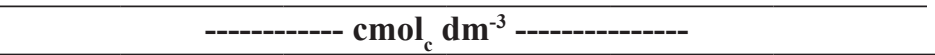 } & _\% \\
\hline 5,3 & 1,7 & 40,6 & 1,1 & 0,5 & 0,3 & 4,4 & 2,0 & 6,1 & 27,8 \\
\hline
\end{tabular}

Análises realizadas no Laboratório de solos e análise foliar segundo metodologia indicada pela EMBRAPA (2013).

para evitar o escorrimento lateral da água após a simulação da chuva e posteriormente a base de cada coluna foi fechada, para evitar perda do material. Na posição vertical as colunas foram mantidas sobre estrados acondicionadas em caixas de madeira e, posteriormente cada uma foi preenchida com solo já umedecido, próximo a capacidade de campo.

O 2,4-D + Picloram, produto comercial (Tordon, 664,3g L-1 de i.a., SL, Dow Agrosciences) foi aplicado nas doses de $1 ; 0,5 ; 0,25 ; 0,125 \%$ da dose de um litro do produto Tordon ${ }^{\circledR}$ para pastagem, correspondendo à $1527 ; 3054 ; 6108$ e $12223 \mathrm{~g} \mathrm{ha}^{-1}$ de picloram e 5729; 11458; 22916 e $45836 \mathrm{~g} \mathrm{ha}^{-1}$ de 2,4-D, respectivamente. Através de pulverizador de pressão constante, as aplicações foram realizadas de forma individual na superfície de cada tubo (posicionado na vertical), aplicando $15 \mathrm{ml}$ da solução por tubo, simulando uma aplicação direta no toco. Após 24 horas, foi realizada a simulação de chuva de $40 \mathrm{~mm}$, mantendo-se os tubos por um período de 48 horas na posição vertical para que ocorresse a percolação.

Após esse período, os tubos foram colocados na posição horizontal, onde foi retirada a tampa lateral do tubo. A semeadura ocorreu logo em seguida, nas profundidades de $0 ; 8 ; 16 ; 24 ; 32$ e $40 \mathrm{~cm}$, onde foram semeadas 3 sementes de pepino (Cucumis sativus) por profundidade, sendo esta utilizada como planta bioindicadora. Foram avaliados 30 tratamentos sendo cinco dosagens do herbicida e seis profundidades analisadas. Para cada tratamento foram analisadas 12 plantas (cada repetição foi utilizada a média de 3 plantas).
Realizou-se o experimento em delineamento inteiramente casualizado, com quatro repetições.

Após 15 dias da semeadura, as plantas foram submetidas à análise das seguintes variáveis:

Fitointoxicação: Atribuíram-se notas de 0 a 10, sendo que a nota 0 foi atribuída às plantas com ausência de sintomas de intoxicação e 10 para a morte das mesmas, de acordo com escala da EWRC (1964) modificada.

Altura: Foi determinado considerando o comprimento do colo até o meristema apical.

Comprimento radicular: As plantas foram cuidadosamente retiradas dos recipientes com auxílio de água corrente e posteriormente o comprimento foi mensurado com o uso de régua graduada.

Área foliar: Foram retiradas somente as folhas verdadeiras, sendo calculadas através do equipamento de área foliar (LI-3100 Area Meter ${ }^{\circledR}$ ).

Os dados obtidos foram submetidos à análise de variância pelo teste $\mathrm{F}$ e as médias comparadas pelo teste Tukey ao nível 5\% de probabilidade. Havendo significância para os fatores quantitativos, foram confeccionados gráficos de regressão. As análises estatísticas foram realizadas com auxílio do software estatístico SISVAR (Ferreira, 2011).

\section{Resultados e discussão}

\section{Fitointoxicação}

Na menor profundidade, independentemente da dose, o nível de fitointoxicação superou os $90 \%$, causando efeito nocivo às plantas de pepino. Porém, com o aumento da profundidade do solo 
o nível de fitointoxicação foi sendo reduzido. Aos $32 \mathrm{~cm}$ de profundidade, as fitointoxicações do pepino variaram entre 1,82 e 2,85 para as doses utilizadas, demonstrando redução do efeito herbicida nessa profundidade (Figura 1).

Estes resultados são semelhantes aos observados por D' Antonino et al. (2009), que estudaram a lixiviação do picloram em solos com $\mathrm{pH}$ de 4,9 submetidos a chuva simulada de $40 \mathrm{~mm}$. Estes autores, observaram elevada intensidade dos sintomas nas plantas cultivadas na parte superior da coluna (superior a $90 \%$ nos primeiros $5 \mathrm{~cm}$ de profundidade), sendo que essa intensidade foi decrescente até $35 \mathrm{~cm}$ de profundidade, no entanto, houve níveis de fitointoxicação em toda coluna.

Nas dosagens entre 0,125 e $0,5 \%$, as plantas só não apresentaram níveis de intoxicação aos $40 \mathrm{~cm}$ de profundidade. Na maior dosagem (1\%), as plantas apresentaram níveis de intoxicação em toda a coluna estudada. Dentre os sintomas de fitointoxicação, a epinastia das folhas, o retorcimento do caule e fortes alterações na altura foram os mais observados entre as plantas, corroborando com os descritos na literatura para esses herbicidas (Silva et al. 2007).

\section{Altura de planta}

As plantas cultivadas na profundidade zero foram fortemente prejudicadas no seu desenvolvimento já na menor dose estudada, havendo inibição da germinação nas demais dosagens. Nas profundidades de 8 e $16 \mathrm{~cm}$, as plantas submetidas a dose de $0,125 \%$ não sofreram alterações significativas na sua altura, porém conforme houve o aumento nas dosagens, verificou-se redução em altura quando comparadas à testemunha.

Nas dosagens entre 0,125 e $0,5 \%$, a partir dos $24 \mathrm{~cm}$ de profundidade, verificou-se uma maior altura das plantas, quando comparado a testemunha. Na maior dose (1\%), o aumento na altura de plantas foi observado a partir dos $32 \mathrm{~cm}$ de profundidade, indicando assim, a presença do herbicida ao longo de toda coluna (Figura 2).
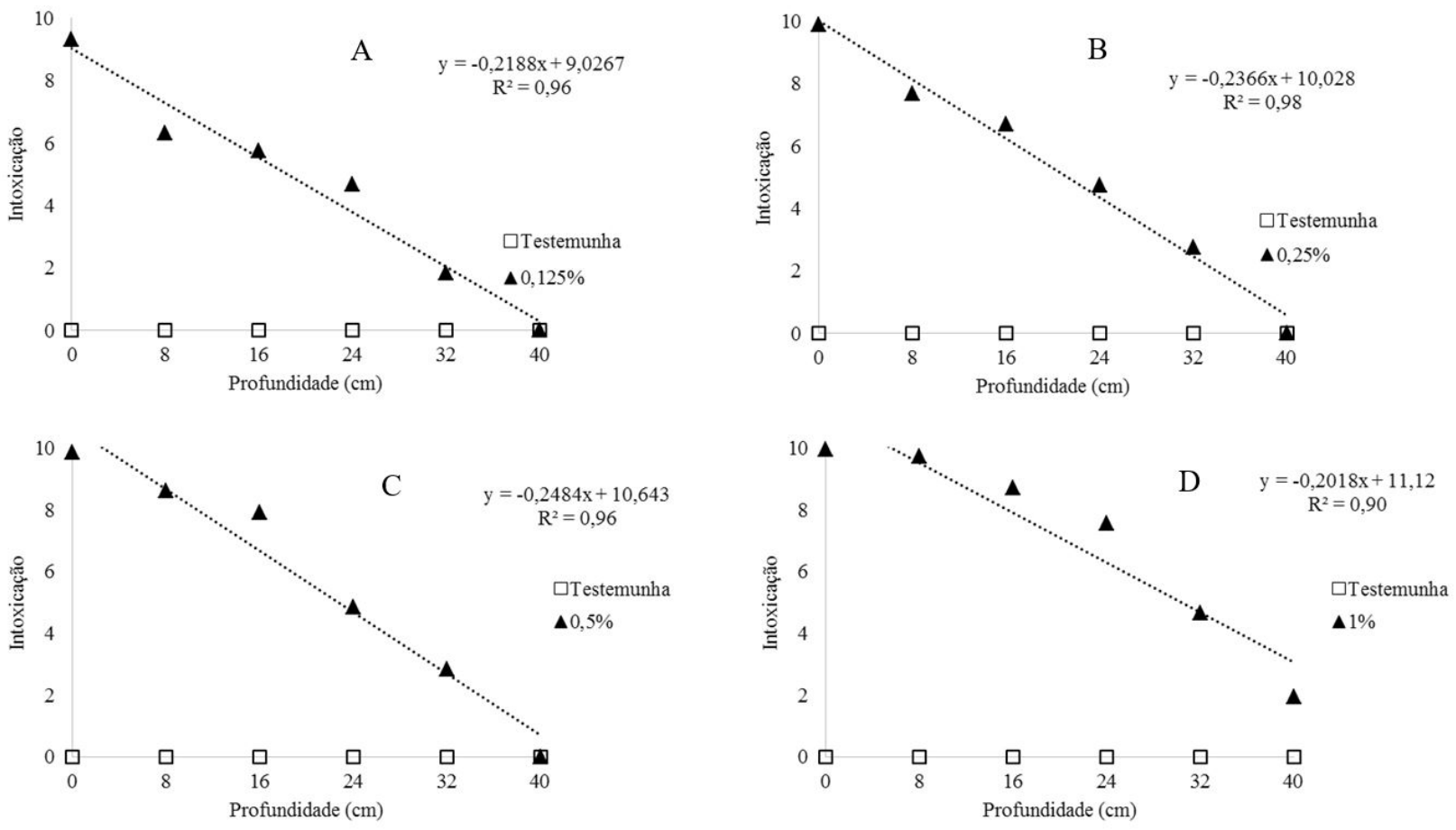

Figura 1. Desdobramento da interação entre profundidades e doses de 2,4-D + Picloram na fitointoxicação das plantas de pepino. (A) testemunha comparada com $0,125 \%$ da dose (de um litro do produto Tordon ${ }^{\circledR}$ ); (B) $0,25 \%$; (C) $0,5 \%$; e (D) $1 \%$. 

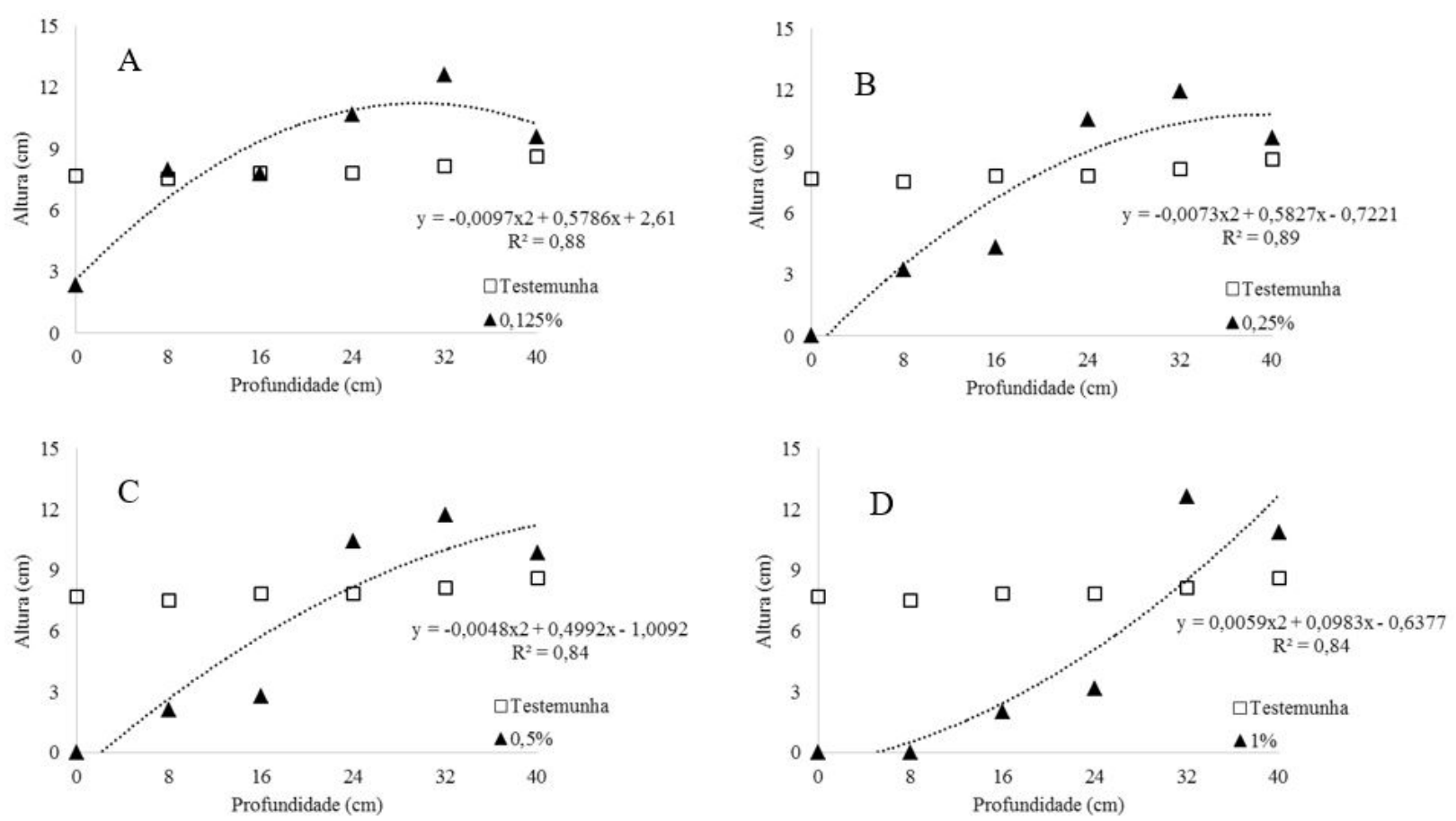

Figura 2. Desdobramento da interação entre profundidades e doses de 2,4-D + Picloram na altura das plantas de pepino. (A) testemunha comparada com $0,125 \%$ da dose (de um litro do produto Tordon $^{\circledR}$ ); (B) 0,25\%; (C) 0,5\%; e (D) $1 \%$.

Herbicidas que pertencem ao grupo dos mimetizadores de auxinas ou reguladores de crescimento, tais como os utilizados no presente estudo, atuam provocando distúrbios no metabolismo dos ácidos nucleicos, aumentando assim a atividade enzimática e a destruição do floema bem como causando alongamento celular, turgescência e rompimento das células (Carmo et al., 2008). De acordo com Guevara (1998), o 2,4-D causa drástico estrangulamento do câmbio, e isso se deve principalmente à inibição da elongação do ramo principal, a qual resulta na diminuição da formação e elongação de nós. Yamashita et al. (2009), verificaram que o herbicida 2,4-D, na dose de 335 g e.a. ha-1 em Ceiba pentandra provocou aumento na altura de plantas.

\section{Comprimento radicular}

Houve redução no crescimento radicular em todas as doses aplicadas, até na profundidade de $16 \mathrm{~cm}$. Na menor dose estudada $(0,125 \%)$, as plantas nas profundidades entre 0,8 e $16 \mathrm{~cm}$ tiveram o desenvolvimento radicular reduzido em 92,7; 46,6 e 30\%, respectivamente, quando comparadas à testemunha. Esse desenvolvimento foi ainda mais reduzido ao se utilizar doses maiores, chegando a reduções acima de 94\% nas mesmas profundidades (Figura 3). Possivelmente, isto se deve ao aumento da enzima celulase nas raízes, levando à rápida destruição do sistema radicular (Thill, 2003).

Observou-se que aos $32 \mathrm{~cm}$ de profundidade nas doses entre $0,125 \%$, e $0,5 \%$, as raízes sofreram efeito hormonal, crescendo além da testemunha. O comprimento se estabilizou aos $40 \mathrm{~cm}$, não havendo diferença significativa entre os tratamentos.

Mesmo não havendo diferença significativa, Fiore et al. (2016), verificou aumento de 35 e $25 \%$ no volume radicular de Terminalia argenteae e Jacaranda puberula respectivamente, quando submetido a tratamento com 2,4-D. D'Antonino et al. (2012) verificaram leve aumento no comprimento 

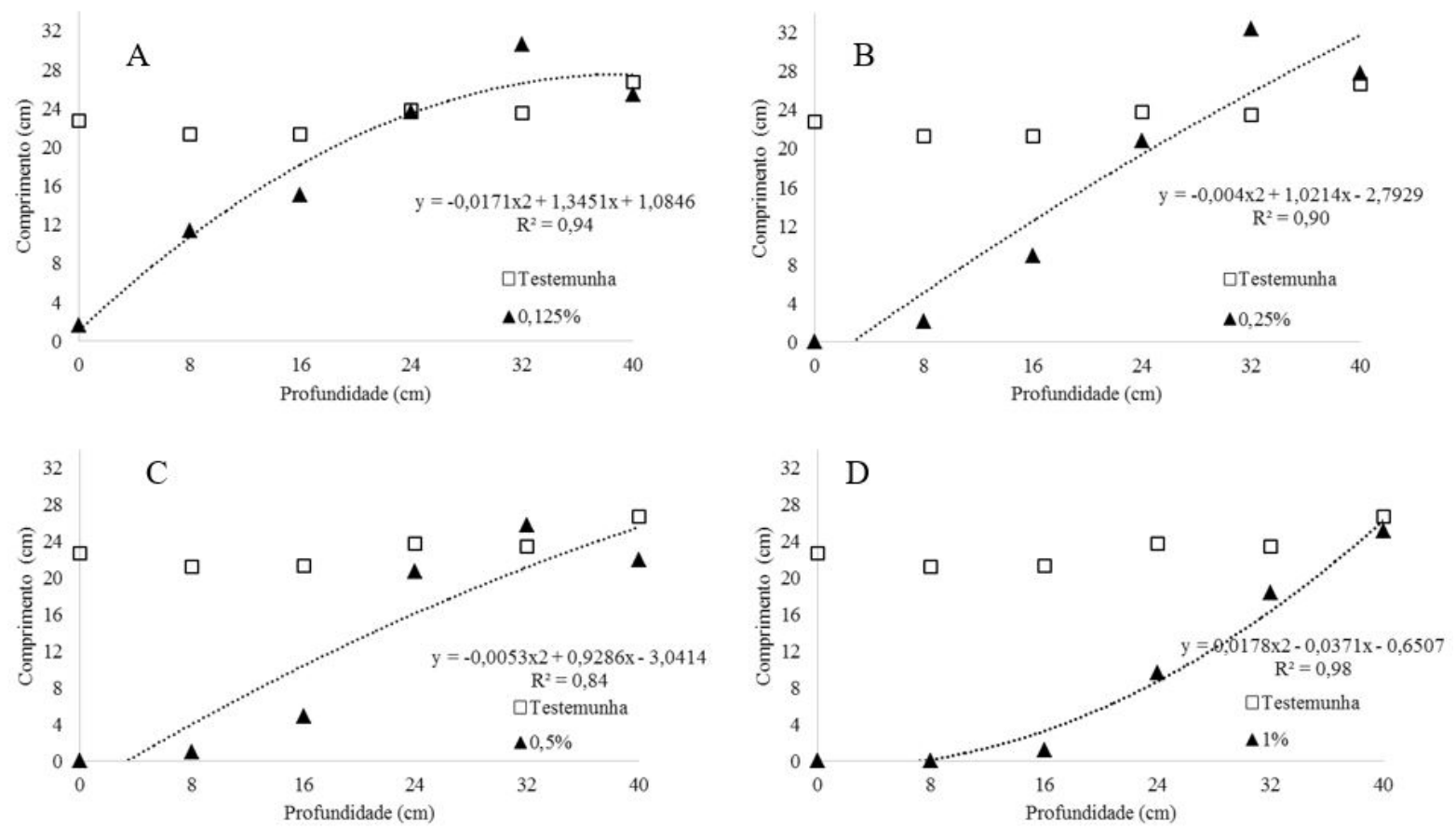

Figura 3. Desdobramento da interação entre profundidades e doses de 2,4-D + Picloram no comprimento radicular das plantas de pepino. (A) testemunha comparada com $0,125 \%$ da dose (1,0 L do herbicida); (B) $0,25 \%$; (C) $0,5 \%$; e (D) $1 \%$.

de raiz de plantas de café em doses de até $60 \mathrm{~g}$ $\mathrm{ha}^{-1}$, porém, conforme houve o aumento das doses o seu comprimento foi afetado significativamente.

\section{Área foliar}

Para esta variável, houve interação entre dose e profundidade $(\mathrm{p}<0,05)$. A lixiviação do 2,4-D + picloram através das colunas de solo foi influenciada conforme a dosagem utilizada. Verificou-se que ao se analisar área foliar das plantas de pepino, o herbicida deslocou-se até $32 \mathrm{~cm}$ de profundidade na menor dose estudada, e chegou aos $40 \mathrm{~cm}$ nas demais dosagens. Observou-se também que, em todas as doses estudadas, nenhuma planta apresentou crescimento de folha verdadeira até os $24 \mathrm{~cm}$ de profundidade e que aos $32 \mathrm{~cm}$ quando apresentou esse crescimento, o mesmo foi limitado devido à ação do herbicida (Figura 4).

Resultado semelhante foi observado por Fiore et al. (2016), em que a área foliar foi significativamente menor para Cedrela fissilis,
Psidium mirsinoides, Tibouchina glandulosa, Handroanthus serratifolius quando submetidas ao herbicida 2,4-D.

Segundo Oliveira e Brighenti (2011), para herbicidas de caráter ácidos como o picloram e o 2,4-D, que têm sua capacidade de dissociação eletrolítica (pKa) igual a 2,3 e 2,8 respectivamente, o $\mathrm{pH}$ é um dos fatores determinantes no comportamento desses produtos no solo, uma vez que determina a forma iônica predominante na solução. Se o pH da solução do solo for igual ao $\mathrm{pKa}$ do herbicida a molécula estará $50 \%$ na sua forma molecular e $50 \%$ na forma aniônica. Como o solo estudado tem o $\mathrm{pH}$ maior que o $\mathrm{pKa}$ do herbicida, a concentração da forma não dissociada é menor que a da forma aniônica, ou seja, o herbicida ficando na forma aniônica, tem mais chances de ser transportados livremente através da solução do solo, justificando a presença do herbicida ao longo da coluna (Silva et al., 2007). 

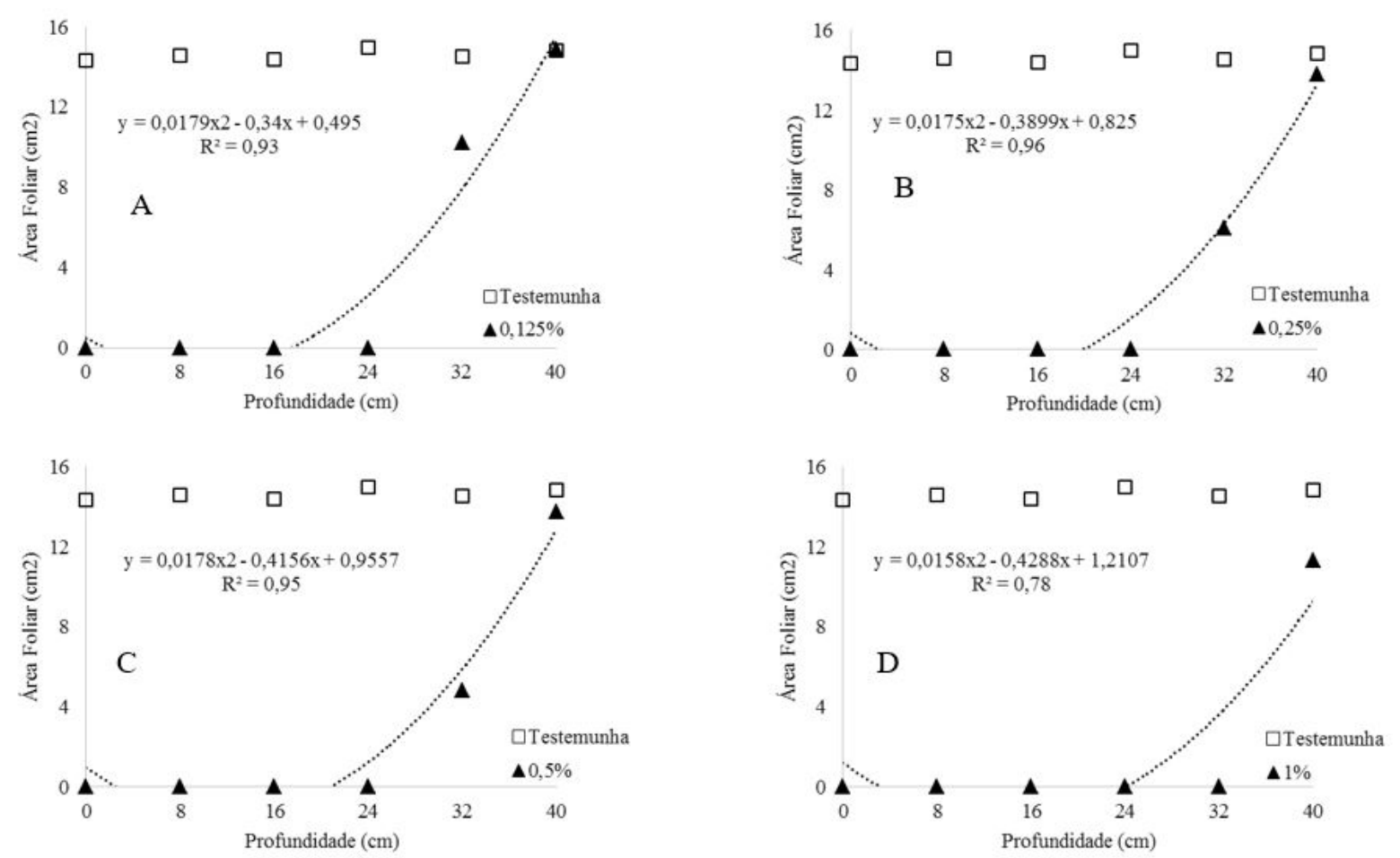

Figura 4. Desdobramento da interação entre profundidades e doses de 2,4-D + Picloram na área foliar das plantas de pepino. (A) testemunha comparada com $0,125 \%$ da dose (1,0 L do herbicida); (B) $0,25 \%$; (C) $0,5 \%$; e (D) $1 \%$.

\section{Conclusão}

Há lixiviação do herbicida 2,4-D + picloram em Latossolo Vermelho Amarelo Distrófico, e maiores concentrações do herbicida, além de atingir regiões mais profundas nas colunas do solo, provocam maiores efeitos tóxicos nas plantas de pepino.

\section{Referências}

Assis, E.C.; D’Antonino, L.; Queiroz, M.E.L.R.; Barbosa, L.C. Leaching of Picloram in ultisol under different rainfall volumes. Planta Daninha, v.29, p.1129-1136, 2011.

Braga, R.R.; Costa, S.S.D.; Ferreira, E.A.; Santos, J.B.; Silva, D.V. Atividade microbiana de solos contaminados com picloram e cultivados com Urochloa brizantha. Enciclopédia Biosfera, v.9, n.17, p.302-314, 2013.
Carmo, M.L.; Procopio, S.O.; Pires, F.R.; Cargnelutti, F.A.; Braz, G.B.P.; Silva, W.F.P.; et al. Influência do período de cultivo de Panicum maximum (cultivar tanzânia) na fitorremediação de solo contaminado com picloram. Planta Daninha, v.26, n.2, p.315-322, 2008.

D’Antonino, L.; França, A.C.; Silva, A.A.; Ferreira, L.R.; Silva, G.R.1. Crescimento de plantas de café em solos com resíduos de picloram. Planta Daninha, v.30, n.1, p.193-200, 2012.

D’Antonino, L.; Silva, A.A.; Ferreira, L.R.; Cecon, P.R.; França, A.C.; Silva, G.R. Lixiviação do picloram em Argissolo Vermelho-Amarelo e Latossolo Vermelho-Amarelo com diferentes valores de pH. Planta Daninha, v.27, n.3, p.589600, 2009.

Dias-Filho, M.B. Diagnóstico das pastagens no Brasil. Belém: Embrapa Amazônia Oriental, 2014. 36p. 
EMBRAPA - Empresa Brasileira de Pesquisa Agropecuária. Sistema brasileiro de classificação de solos. 3.ed. Brasília, 2013. 353p.

EWRC - European Weed Research Council. Report of $3 \mathrm{rd}$ and $4 \mathrm{rd}$ meetings of EWRC: cittee of methods in weed research. Weed Research, v.4, n.1, p.88, 1964.

Ferreira, D.F. Sisvar: a computer statistical analysis system. Ciência e Agrotecnologia, v.35, n.6, p.1039-1042, 2011.

Fiore, R.A.; Santos, J.B.; Ferreira, E.A.; Cabral, C.M.; Pereira, I.M. Growth and nutritional analysis of tree species in contaminated substrate by leachable herbicides. Revista Árvore, v.40, p.585-594, 2016.

Guevara, G. Efecto del 2,4-D sobre el algodón. Saenz Peña: Instituto Nacional de Tecnologia Agropecuária, 1998. 12p. (Boletim Técnico, 12).

Mancuso, M.A.C.; Negrisoli, E.; Perim, L. Efeito residual de herbicidas no solo ("Carryover"). Revista Brasileira de Herbicidas, v.10, n.2, p.151-164, 2011.

Oliveira, M. F.; Brighenti, A. M. Comportamento dos herbicidas no ambiente. In: Oliveira Júnior. R. S.; Constantin. J.; Inoue, M. H. (Ed.). Biologia e manejo de plantas daninhas. Curitiba: Omnipax, 2011. p.263-304.

Pellegrini, L.G.; Nabinger, C.; Neumann, M.; Carvalho, P.C.F.; Crancio, L.A. Produção de forragem e dinâmica de uma pastagem natural submetida a diferentes métodos de controle de espécies indesejáveis e à adubação. Revista Brasileira de Zootecnia, v.39, n.11, p.23802388, 2010.

Possamai, A.C.S. Potencial de lixiviação dos herbicidas diuron e (diuron + hexazinone + sulfometuron) em solos com texturas contrastes. 2012. 38 f. Dissertação (Mestrado em Produção Vegetal) - Unidade Universitária de Aquidauana, Universidade do Estado de Mato Grosso do Sul, Aquidauana, 2012.

Santos, M.V.; Freitas, F.C.L.; Ferreira, F.A.; Viana, R.G.; Tuffi Santos, L.D.; Fonseca, D.M. Eficácia e persistência no solo de herbicidas utilizados em pastagem. Planta Daninha, v.24, n.2, p.391-398, 2006.

Silva, A.A.; Vivian, R.; Oliveira Júnior, R. S. Herbicidas: comportamento no solo. In: Silva, A.A.; Silva, J.F. (Ed.). Tópicos em manejo de plantas daninhas. Viçosa: Universidade Federal de Viçosa, 2007. p.189-248.

Thill, D. Growth regulator herbicides. In: Thill, D. Herbicide action course. West Lafayette: Purdue University, 2003. p.267-291.

Yamashita, O.M.; Betoni, J.R.; Guimarães, S.C.; Espinosa, M.M. Influência do glyphosate e 2,4D sobre o desenvolvimento inicial de espécies florestais. Scientia Forestalis, v.37, n.84, p.359366, 2009. 